excellent forestry school at Zurich. In France not only does the State manage its own forest property in approved manner, and supervise the management of forests belonging to communities and other public institutions, but it extends its control over private forests by forbidding any clearing except with the consent of the forest administration.

Sir Robert Ball commences a series of articles on "The Great Astronomers" in Good Words, the subject of his sketch this month being Tycho Brahe. Dr. Dreyer's book on "The Life and Work of Tycho Brahe" has furnished the author with most of his facts, so the article can hardly be abstracted, and there is nothing in it to comment upon. Mrs. Percy Frankland contributes an article entitled "Half an Hour with the Microbes," and manages to compress a large amount of information in few pages. An article by Sir Herbert Maxwell, headed " Assisted Sight," will be found interesting to Selbornians, for it deals with the sights of bird-life and movement which a spyglass reveals to him who will be at the trouble to carry it.

A passing notice must suffice for the other magazines received by us.

In Longman's, Mr. C. T. Buckland, a cousin of the late Frank Buckland, describes some of his personal experience with alligators, and W. Schooling recounts some of the myth and marvels concerning the Pleiades. Lord Lilford writes upon the destruction of wild birds in the National Review. He considers that the legal protection of eggs under specific names is impracticable, if not utterly impossible. The National also contains an article of interest to nature lovers, by "A Son of the Marshes." Two articles of more or less scientific interest appear in Chambers's Journal, one on "The Smoke Problem," the other on the new powder, Amberite. Mr. Phil Robinson contributes to the Contemporary a description of natural object in spring, in which poetical fancy is happily blended with scientific observation. Serpent-worship, and the serpent's strange appearance and manner of progression, is Mr. W. H. Hudson's theme in the Fortnightly. Mr. R. B. Anderson describes, in Scribner, a winter's journey up the coast of Norway, and Mr. Morley Roberts writes on cannibalism in the Humanitarian.

\section{DUST AND METEOROLOGICAL} PHENOMENA.

$\mathrm{I}$ this communication are given tables containing over 1000 observations of the dust particles in the atmosphere, alon with simultaneous observations on other meteorological phenomena, made by the author during the years 1891,1892 , and $r 893$. In Parts $i$. and ii. on the same subject are nearly 500 similar observations, made at the same places, during the two preceding years; so that there are in all now over 1500 observations of atmospheric dust, to produce which required the testing of over 15,000 samples of air. With such a number of observations it seemed not unreasonable to expect that more definite results could now be worked out than were possible before.

At the beginning of the paper reference is made to obser vations made in the south of France, at Hyères, Cannes, and Mentone. After this the observations made at the Italian lakes are described. At none of the places in these districts was very pure air ever met with. No air with a smaller number of particles than 600 per c.c. was tested.

At Baveno, in addition to the usual test at low level, a number were made at different elevations on the slopes of Monte Motterone, with the following results. With the wind blowing up the slopes, the means of seven observations gave the following number of particles per c.c. at the different levels :-

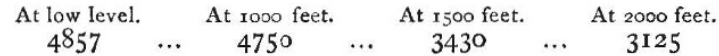

And the mean values of eight observations when the wind did not blow up the slopes :-

$$
\begin{array}{ccccccc}
\text { At low level. } & & \text { At } 1000 \text { feet. } & & \text { At } \mathbf{3} 500 \text { feet. } & & \text { At } 2000 \text { feet. } \\
4743 & \ldots & 3270 & \ldots & 2195 & \ldots & 1453
\end{array}
$$

Thus with the wind blowing up the slopes, and carrying up the impure air, the amount of dust at 2000 feet was only reduced

1 Abitract of paper read before the Royal Society of Edinburgh, by John Aitken, F.R.S., on February 19. (Communicated by permission of the Cuuncil of the Society.)

$$
\text { NO. I } 275 \text {, VOL. } 497
$$

to 0.64 of the number at low level, while if the wind was from other directions it was reduced to $0^{\prime} 3$

The observations made on the Rigi Kulm during three visits, of a week each, in the different years are then discussed, and the conditions existing during each day described separately along with the different meteorological phenomena witnessed on the different days. The conclusion arrived at in the previous visits as to the exaggerated descriptions given by many writers, of the beauty of the colouring on earth and sky seen a high level at sunrise and sunset, is entirely confirmed. During the visit, in the five years no colouring at sunrise or sunset has been witnessed from the Rigi equal to what is frequently seen at low level.

The observations show that the sunset colours depend very much on the amount of dust in the air. When the atmosphere is comparatively free from dust the colouring is cold, but the lighting is clear and sharp; and when there is much dust, there is more colour on the mountains and clouds, and in the air itself, and the colouring is warmer and softer. At high level the colouring is not only more feeble, but it is also of shorter duration. A thick veil of haze seemed to hang in the air between the observer and the mountains on all days when the number of particles was great, and it became very faint when the number was small.

The paper then proceeds to investigate the effect of the direction of the wind on the number of particles at this station, and discusses the conditions with the aid of the dust observations and the weather charts of Switzerland-the general air calculation over Switzerland being obtained from the reports of the high level observatories, namely the Santis, St. Gothard, and Pilatus, and low level currents from the reports of the low level observing stations. The results of this investigation are summed up in two tables. In one of these tables are given the highest and lowest numbers observed when the wind was south erly and blew from the pure area of the Alps; and in the other, the observations when the wind was from the inhabited parts of Switzerland. The following are the means of all the observations :-

$\begin{array}{lrrrrr}\begin{array}{c}\text { Direction of } \\ \text { wind. }\end{array} & \begin{array}{c}\text { Highest } \\ \text { number. }\end{array} & \begin{array}{r}\text { Lowest } \\ \text { number. }\end{array} & \begin{array}{c}\text { State of the air. } \\ \text { Wind from Alps }\end{array} \\ \ldots & \mathbf{1} 305 & \ldots & 42 \mathrm{r} & \begin{array}{c}\text { Clear to very clear. } \\ \text { Wind }\end{array} \\ \text { Wind from plains } & \ldots & 5756 & \ldots & \mathbf{1 0 6 3} & \text { Medium to thick. }\end{array}$

The condition of the air on the occasions of the different visits to the Rigi varied greatly. During the visit in 1889 , the wind always blew from the Alps, the number of particles was low, and air very clear. During the visits in 1892 and 1893 , the wind never blew steadily for any length of time from the pure direction, the air was always much hazed, and the number of particles great.

The effect of the amount of dust on the transparency of the air on the Rigi is then discussed. The above table, showing the effect of the direction of the wind on the number of particles, also shows the effect of the dust on the transparency. On all days when the wind was southerly, and the number of particles low, the air was clear, or very clear; whereas when the wind blew from the plains, and the number went high, the air was always greatly hazed. The effect of the dust on the transparency is then shown in another way, the result being given in the following table, in which are entered the number of times Hochgerrach was visible, and the condition of the air at the

\begin{tabular}{|c|c|c|c|c|c|}
\hline $\begin{array}{c}\text { Number of } \mathrm{ti} \\
\text { visible. }\end{array}$ & mes & $\begin{array}{l}\text { Amount of haze } \\
\text { on Hochgerrach. }\end{array}$ & & $\begin{array}{l}\mathrm{N} \text { umber of par- } \\
\text { ticles per c.c. }\end{array}$ & $\begin{array}{l}\text { Wet bulb } \\
\text { depression. }\end{array}$ \\
\hline 8 & . & $\frac{1}{4}$ to $\frac{1}{3}$ & & 326 to $850 \ldots$ & $10^{\circ}$ \\
\hline 2 & $\cdots$ & $\frac{3}{4}$ & $\cdots$ & I 375 to $1575 \ldots$ & to $8^{\circ}$ \\
\hline 3 & $\cdots$ & Just visible & $\cdots$ & I 825 to $2050 \ldots$ & $4^{\circ} \mathrm{t}$ \\
\hline
\end{tabular}
time as regards haze, dust, and humidity :-

Hochgerrach is situated at a distance of about seventy miles from the Rigi, in an easterly direction ; its visibility, therefore, may be taken as an indication of very clear air. The above table shows that it was visible on thirteen occasions. On eight of these it was only from $\frac{1}{1}$ to hazed, and the number of particles was at a minimum. 'The table also shows that as the number of particles increased the haze also increased, and at last the mountain became invisible when the number went a little over 2000 per c.c. As the number of particles frequently remained above 2000 for days at a time, Hochgerrach could only be seen at intervals.

The paper then passes on to consider the daily maximum on 
the Rigi. The daily maximum does not appear on all days ; winds from pure directions generally prevent it, either by checking the ascent of the valley air, or by the valley air being pure, or by the pure valley air not being much heated by the sun, and therefore having but little tendency to rise. The daily maximum is very marked when the wind is from the plains. The hour at which the rise in numbers begins and the hour of maximum are very irregular. Sometimes the rise begins in the morning, but sometimes it is the afternoon before it puts in its appearance. The maximum number is generally attained some time in the afternoon, if not checked at an earlier hour by change of wind, or by clouds. The amount of the daily maximum varies greatly; sometimes it is only two or three times the morning number, but it has been observed as much as eight times.

While on the Rigi the author had frequent opportunities of observing the well-known tendency of Pilatus to be shrouded in cloud. The clonding was frequently observed to extend down the slopes far below the level of the Rigi Kulm, while the Rigi kept free of cloud. It is shown that this greater cloudiness of Pilatus is only what might be expected from the nature of the surroundings. The Rigi is a true isolated mountain, whereas Pilatus is not, though it looks quite as isolated as the Rigi from many points of view. It is, however, only the terminal peak of a very long wall of mountains extending in a westerly direction for about twenty-five miles. As the upper ridges of this wall are from 6000 to 7000 feet high, all winds from the north and west are compelled to rise when they meet this barrier, and in rising condensation takes place; whereas winds from all directions can pass on all sides of the Rigi, and are not compelled to rise to the same amount. It is well known that the north and west win is cause Pilatus to be clouded, and these are the winds specially compelled by the Pilatus range to rise and to form clouds.

The observations made at Kingairloch, in Argyllshire, are then described, along with a parallel series of observations made at the same hours on Ben Nevis. Diagrams are given sh wwing the conditions at the two stations during July in the different years. Attention is first drawn to some very abnormal dust readings obtained at Kingairloch. During north-west winds the number of particles is generally very low, but on the afternoons of some days the numbers went high. It was found that these abnormal reading; were always accompanied by certain conditions of weather: if the sky remained completely clouded all day, the numbers were aiways low during the whole of the day; but, on the other hand, if breaks formed in the clouds, the number began to rise, and the increase was very much in proportion to the amount of clear sky. It is also shown that these abnormal readings came far more frequently with anticyclonic than with cyclonic circulation; but as these are the conditions which bring more or less cloudy skies, they do not seem to have much infu ence in themselves. Tests were made to see if the abnormal readings were due to local impurity, but no evidence of this could be obtained. The fact that they come and go with sunshine seems to negative any such idea; at least, if they are local, they must be of a nature of which at present we know nothing. It is suggested that it may be possible that sunshine under certain conditions may produce some change in the constituents of our atmosphere, which gives rise to something that forms a nucleus in saturated or supersaturated air. The fact that during the days of abnormally high readings the air did n t become hazed to anything like the extent indicated by the number of particles, seems to suggest that these nuclei are of molecular dimensions, and it is even possible they may not be nuclei at all while the air is dry, but form nuclei in saturated air. Nothing corresponding to these abnormal readings can be discovered in the observations made at other places. In discussing the effects of dust, these abnormal readings lave been omitted, and the mean of the morning and evening figures taken as the number for the day.

The investigation of the amount of dust, and the direction of the wind, shows that winds from the north-west quadrant are the purest at this station, and those from the south-east quadrant the most impure. All the high readings at $\mathrm{B} \in \mathrm{n}$ Nevis were observed in south-east winds. The effect of the direction of the wind is shown by diagrams, the dust curves being low with north-westerly, and very high with south-eavterly winds.

The next point discrssed is the relation between the trans. parency of the atmosphere and the number of dust particles.
The observations made during the last three years, as in the previous two, show that on all days when the number was small the air was clear, if the wet bulb depression was over $2^{\circ}$. In order to make the haze observations more satisfactory, it has been the custom for the last three years to enter in the notes the limit of visibility in miles at the hour the other observations were taken. This is done by estimating the amount of haze on a mountain at a known distance, and calculating the extreme limit it would be visible at in the same air. In working out the relation between the number of particles and the transparency, it is necessary to reject all observations made during rainy or donbtful weather. For reasons frequently explained, the observations were separated into sets, according to the humidity at the time; all the observations taken when the wet-bulb depression was from $2^{\circ}$ to $4^{\circ}$ being entered in one table, all those when it was from $4^{\circ}$ to $7^{\circ}$ in another, and all when it was $7^{\circ}$ to $10^{\circ}$ in a third. In the tables were entered the highest, lowest, and mean numbers of particles observed, while the conditions remained at all steady, and in another column was entered the limit of visibility at the time. The different observations were arranged in the tables in the order of the mean number of particles, beginning at the top with the observation with the least number, and ending at the foot with the observation with the greatest number. This will be easiest understood by an example. The following table represents in abstract one of the tables with the Kingairloch observations for 1893, when the wet bulb depression was from $4^{\circ}$ to $7^{\circ}$. As it is unnecessary to give all the observations, only the first and last are entered.

$$
\begin{aligned}
& \text { Date. } \begin{array}{rll}
\text { Lowest } \\
\text { number. }
\end{array} \text { Highest } \begin{array}{c}
\text { Mean } \\
\text { number. }
\end{array} \text { number. } \begin{array}{c}
\text { Limit of } \\
\text { visibility } \\
\text { in miles. }
\end{array} \quad \text { C. }
\end{aligned}
$$

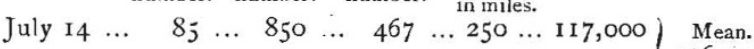

$$
\begin{aligned}
& \left.\begin{array}{llllllllllll}
\text { July } & 2 & \ldots & 1600 & \ldots & 2400 & \ldots & 2000 & . . & 40 & \ldots & 80,000
\end{array}\right\} 106,000
\end{aligned}
$$

If we look down the column headed limit of visibility in the different tables, it is seen that in all of them the highest limit of visibility is always associated with the least amount of dust, and the least limit with the greatest amount of dust. The tables show clearly that the amount of haze depends directly on the number of dust particles in the air. It seemed probalile that the same number of particles would produce the same amount of haze, whether these parlicles be distributed through a long or short length of air. If this be so, then the mean number of particles multiplied into the limit of visibility ought to be a constant. In the tables are columns headed $\mathrm{C}$, in which the numbers so calculated are entered. From the tables it is seen that though the values of $C$ for the different observations are not alike, yet they agree as well as cou'd be expected, considering the difficulty in estimating the amount of haze and the probable variations in the size of the dust particles, which would influence their hazing effect. The tables for the Kingairloch observations in 1893 show that when the wet bulb depression was between $2^{\circ}$ and $4^{\circ}$ the value of $\mathrm{C}$ was 77,000 ; when the wet bulb depression was from $4^{\circ}$ to $7^{\circ} \mathrm{C}$ was equal to 106,000 (see table above), and when the wet bulb depression was from $7^{\circ}$ to $10^{\circ}$ the value was I4 I, 000.

The Kingairloch observations, when arranged in these tables, show the effect of the humidity, as well as of the dust, on the transparency. The value of $\mathrm{C}$ when the wet bulb depression is from $2^{\circ}$ to $4^{\circ}$ is only about one-half of what it is when the depression is from $7^{\circ}$ to $10^{\circ}$. The damper air has therefore nearly double the hazing effect of the drier, because $C$ is proportional to the number of particles required to produce a complete haze, that is, a haze thick enough to shut out all view. What that number of particles really is, is obtained by multi-

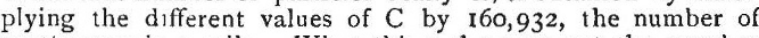
centimetres in a mile. When this is done we get the number of particles of dust per square centimetre, and of lengths of from to to 250 miles required to produce complete haze in air giving different wet bulb depressions.

$$
\begin{array}{ccc}
\text { Wet bulb depression. } & & \begin{array}{c}
\text { Number of particles required } \\
\text { to produce complete haze. }
\end{array} \\
2^{\circ} \text { to } 4^{\circ} & \ldots & \mathbf{1 2}, 500,000,000 \\
4^{\circ} \text { to } 7^{\circ} & \ldots & \mathbf{1 7}, 100,000,000 \\
7^{\circ} \text { to } 10^{\circ} & \ldots & 22,600,000,000
\end{array}
$$

Ti.e above figures show the effect of the humidity very clearly. Nearly double the number of particles are requircd to produce 
the same amount of haze when the air is very dry than when it is dampish. It will also be noticed that the transparency of the air is rougbly proportional to the wet bulb depression. It should be noted that it is not the amount of vapour in the air that produces this effect, but the nearness of the vapour to the dew point which seems to enable the dust particles to condense more vapour by surface attraction and otherwise, and thus, by becoming larger, they have a greater hazing effect. The above table shows the relation between the humidity, the dust, and the transparency, so that knowing any two of them we can calculate the third.

The paper then proceeds to an examination of the relation between the dust and the haze from the Ben Nevis reports for the periods of the Kingairloch observations, when it is seen that on all days when the air was very clear the number of particles was small at high and low levels, and the transparency was least when the amount of dust was greatest. On one nccasion Ireland, which is 125 miles distant, was seen from Ben Nevis, and only a thin haze was visible. On that day the number was about 200 per cc. at low level, and under 200 at high level, and, as the numbers remained very constant at both levels all day, this day may be looked upon as one of the purest as well as one of the clearest observed.

The next set of observations discussed are those made at Alford, in Aberdeenshire. The air at that station was always very pure, except when the wind was southerly, and brought impure air from the inhabited districts. The values of $\mathrm{C}$ for the different humidities were calculated from the Alford observations, and the results will be found in the following table. When at Alford some observations were made on Callievar, a hill about $\mathbf{I} 747$ feet high. The values of C from three observations made on Callievar do not agree with the others, being only about one-half as great.

The difference in the value of $\mathrm{C}$ obtained from the Callievar observations opened up the question of the value of $\mathrm{C}$ as obtained from observations at low level. The difference in the two values might be due to the tests at low level being made in locally impure air, near the surface of the earth, while the estimates of haze are made partly through purer upper air, and in calculating the value of $\mathrm{C}$ it is assumed that the air all through the length in which the haze is estimated has the same amount of dust as at low level, whereas it may have less. If, then, the low level observations be made in polluted areas, they will give too high a value for $\mathrm{C}$. The difference between the amount of dust at Kingairloch and Ben Nevis does not, however, account for anything like the difference given by the Callievar observations. As there were only three observations made on Callievar, it was thought as well to test this point by working out the values of $\mathrm{C}$ trom the Rigi observations. When this was done they were found to be similar to those for the Kingairloch observations. The following table shows the different values of $C$ at the different wet bulb depressions, calculated from the different sets of observations :-

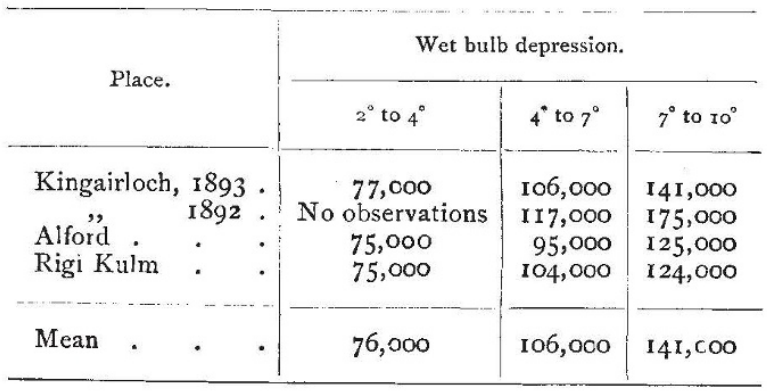

What are called purifying areas in this paper are those regions on the earth's surface in which the air loses more impurity than it gains. In all densely-inhabited areas it loses its purity, and in all uniuhabited ones it tends to regain it; but all uninhabited areas are not equally good purifying ones. Much of the dusty impurity discharged into our atmosphere from artificial sources, by voleanoes, and by the disintegration of meteoric matter, falls to the ground, but much of it is so fine it will hardly settle. The deposition of vapour on these very small particles seems to be the method adopted by nature for cleansing them away; they become centres of cloud particles, and ultimately fall with the rain. It may be remarked that all very low numbers

$$
\text { Nu. I } 275 \text {. VOL. 49] }
$$

at Kingairloch were obtained in close misty rain, and in the clouds near the earth, in the very area in which the dust was being used up. This experience is confirmed by the observa. tions made on Ben Nevis. From this it might be expected that the areas where most clouds form, and most rain falls, will have the greatest purifying influence. This conclasion is confirmed by the dust observations made in air coming from four great purifying areas, namely, the Mediterranean, the Alps, the High lands of Scotland, and the Atlantic. The following figures show the mean values of the lowest readings observed in each of the five years in air coming from these areas; the Mediterranean, $89 \mathrm{I}$ per c.c. ; the Alps, $38 \mathrm{I}$; the Highlands, I4I ; and he Atlantic, 72. It should be noted that these are not the mean numbers, but the mean of the lowest, and represent the maximum purifying power of the different area:.

\section{UNIVERSITY AND EDUCATIONAL INTELLIGENCE.}

THE sixth summer meeting of University Extension and other students will be held in Oxford from July 27 to August 24 . Courses of study are provided in numerous subjects of interest and importance. Among the science courses are included lectures on ,hysical problems relating to astronomy, by Dr. A. H. Fison. Mr. Henry Balfour, Curator of the Pitt-Rivers Museum, will lecture upon the arts of mankind and their evolution, illustrating his discourses by specimens exhibited in the museum. Geology, both lectures and field work, has been undertaken by Prof. A. H. Green, F.R.S. Dr. C. H. Wade will conduct lectures and classes in hygiene, and Mr. J. E. Marsh have charge of students in courses of practical chemistry at the chemical laboratory in the University Museum. A lecture on colour vision will also be given by Captain W. Abney. In adidition to these courses, and many others on history, literature, economics, and art, there will be a course on the science and art of education, comprising lectures on psychology, the theory of education, and the educational systems of England, France, and Germany. Instruction in wood-carving, Sloyd, and photography can also be obtained at the meeting.

THE Oxford University Extension Gazette announces that the council of the London Society for the Extension of University Teaching has decided to hold in London, on June $\mathbf{2 2}$ and 23 , a conference representative of all the authorities concerned in the work of University Extensiin. The purpose of the conference will be to sum up and present the educational results of University Extension work since the inauguration of the movement, and to discuss practical proposals and a general policy for the future in the light of past experience. Official representatives of the Universities of Oxford, Cambridge, and London will be asked to preside over the three sessions of the conference, wh:ch by emphasising the unity of the University Extension system, will doubtless increase public interest in this branch of educational work.

\section{SCIENTIFIC SERIALS.}

Builetin de l'Academie Royale de Belgique, No. r.-Anothex word on the definition of latitude, by $\mathrm{F}$. Fulie. If a displacement of the pole of inertia really exists, the difference between the astronomical latitudes of two places situated upon opposite meridians, such as Berlin and Honolulu, will be positive in summer alid negative in winter. It is therefore best to take as a point of reference, not the instantaneous pole, but the mean position of the pole of inertia, i.e. the geographical pole. As regards the direction of displacement of the pole of inertia, M. Folie's latest conclusion is that it is retrograde, with a period of 321 instead of 423 days. - Explanation of the systematic differences between the catalogues of Greenwich, Melbuurne, and the Cape, by diurnal nutation and the anuual displacement of the pole of inertia, by the same author. The hitherto unexplained systematic differences between the three catalogues are eliminated by the introduction of the constant term entering into the expression for diurnal nutation.-A new gradual synthesis of benzene, by Maurice Delacre. This synthesis starts, like the one previously described, with acetophenone, and passes through dypuone and dypnopinacone to the $\gamma$ varieties (not the $a$ series) of dypnopinacoline, dypnopinalcohul, and dypnopinalcolene to triphenylbenzine.-Application of the refractometer 